American Philosophical Quarterly

Volume 57, Number 3, July 2020

\title{
WHAT ARE THE ODDS THAT EVERYONE IS DEPRAVED?
}

\author{
Scott Hill
}

ABSTRACT

Why does God allow evil? One hypothesis is that God desires the existence and activity of free creatures but He was unable to create a world with such creatures and such activity without also allowing evil. If Molinism is true, what probability should be assigned to this hypothesis? Some philosophers claim that a low probability should be assigned because there are an infinite number of possible people and because we have no reason to suppose that such creatures will choose one way rather than another. Arguments like this depend on the principle of indifference. But that principle is rejected by most philosophers of probability. Some philosophers claim that a low probability should be assigned because doing otherwise violates intuitions about freewill. But such arguments can be addressed through strategies commonly employed to defend theories with counterintuitive results across ethics and metaphysics.

\section{INTRODUCTION}

1 magine God is deciding what to create. One of His options is to create free creatures. One of the things informing His decision is knowledge about what those creatures would do. If He were to create St. Francis and put him in the mountains, he would freely choose to contemplate the beauty of nature. If $\mathrm{He}$ were to create me and allow me to be offered a bribe, I would freely choose to take the bribe. There seem to be truths about what free creatures like us would do if we were put in various circumstances. And, in deciding who to create and what circumstances to arrange, it seems that God is informed by these truths. Finally, it seems that such truths are not decided by God. For if they were, the creatures those truths are about would not be free. This is the Molinist doctrine of God's providence.
Suppose Molinism is true. Then what are the odds that no matter who God created or what circumstances He put them in, they would do evil? According to a common claim, the odds are very small. I argue that a lesson from the fine-tuning literature casts doubt on this claim. I then reply to a series of objections. The objections may be addressed by combining further applications of the lesson with assumptions available to the Molinist about probability, freewill, observational bias, error theory, explanation, and paraphrase. This is relevant to theodicy. If God were unable to create a world with free creatures but no evil, it would form part of the explanation of why God allows evil.

\section{THE LESSON}

The universe appears to be fine-tuned for life. Take, for example, the gravitational constant. Our best physics tells us that the 


\section{0 / AMERICAN PHILOSOPHICAL QUARTERLY}

gravitational constant did not have to take the value it actually took. It could have been anything from zero to infinity. Our best physics also tells us that if the gravitational constant had been slightly different, then life would not exist. A natural reaction to this is to think that it must have been very unlikely that the universe would be life permitting. But what is the motivation for this reaction? The standard view is that it is motivated, often just implicitly, by the following line of reasoning: Only a very small range of the values the gravitational constant could have taken are life permitting. We have no reason to think it was more likely to take any one of these values than any of the others. So, we should assign equal probability to each of the values it could have taken. Such an assignment makes it very unlikely that the gravitational constant would fall within the life permitting range. This reasoning relies on:

Indifference: Whenever there is no evidence favoring one possibility over another, they have the same probability.

Indifference is rejected by some philosophers due to Bertrand's Parado: Imagine a factory produces cubes with side-length between zero and one foot. The question "What is the probability that a randomly chosen cube has side length between zero and half a foot?" is logically equivalent to the question "What is the probability that a randomly chosen cube has face area between zero and one fourth square feet?" However, applying Indifference to the first question gives the result that the probability is one half. And applying Indifference to the second question gives the result that the probability is one fourth. So, Indifference gives inconsistent answers to logically equivalent questions. And it must be rejected.

Setting aside Bertrand's Paradox, there are two remaining problems. First, there is the Normalization Problem. It is impossible to apply Indifference to cases involving infinitely many possibilities in such a way that the sum of all the relevant probabilities adds up to one. As McGrew, McGrew, and Vestrup (2001, pp. 1031-2) put it:

[T] here is no way to "add up" the regions . . . so as to make them sum to one. If they have any sum, it is infinite. .. Working from bare logical possibilities, it seems unreasonable to suggest that any one range of values for the constants is more probable a priori than any other similar range.

Second, if we say that the probability of such possibilities is zero, then this leads to the Coarse-Tuning Problem. No matter how big the life permitting region turned out to be, the probability that the gravitational constant would fall within that region is zero. As Colyvan, Garfield, and Priest (2005, pp. 327-8) put it:

[S]imilar reasoning shows that an infinitely sharp dart cannot hit a dart board, no matter how big the board is; or that no one can win a lottery that has infinitely many tickets. ... This does not, however, relieve the defender of the finetuning argument of the burden of proof. Anyone advancing this argument must demonstrate that the probability that the physical constants take life-supporting values is low.

Given the small life permitting range of values the gravitational constant could have taken, it is tempting to infer that a world with life has a low probability. But this inference is based on Indifference. And Indifference is false. The motivation for the claim that it is unlikely that the universe would be life permitting is significantly reduced. This suggests ${ }^{2}$ :

The Lesson: Do not use Indifference to assign probabilities in ignorance, especially when the number of possibilities is infinite.

\section{Depravity}

Consider Counterfactuals of Freedom. Let $\mathrm{S}$ be a subject, $\mathrm{A}$ be an action, and $\mathrm{C}$ be a 
complete specification of the laws of nature and the history of the world up to the instant of time at which $\mathrm{S}$ is faced with the decision to A. Now consider: "If $S$ were in $C$, then $S$ would freely perform A." Any counterfactual with a form like this is a counterfactual of freedom. Next, consider Libertarianism. This is the view that a subject's performance of an action is free only if the history of the world together with the laws of nature do not entail that the subject performs that action. Molinism, then, is the doctrine that libertarianism is true ${ }^{3}$, that some counterfactuals of freedom are true and have their truth-values prior to creation, that their truth-values are not up to God, that God knew the truth-values of all counterfactuals of freedom prior to creation, and that God made use of this knowledge in His decision about what to create. Let's also assume that God has the traditional attributes including omnipotence, omniscience, and omnibenevolence. Finally, let's say that a circumstance for a free creature is any situation in which that creature is allowed to make a free decision. Now consider ${ }^{4}$ :

Depravity: If Molinism is true, then no matter who God created and no matter what circumstances He put them in, they would have done evil.

Many people claim that we should assign a low probability to Depravity. As Adams (1977, pp. 116-7) puts it:

It is worth asking, therefore, whether the hypothesis of universal trans-world depravity is plausible. ... [T]here is an infinite variety of natural and supernatural ways in which God can work on us. ... Molina held that both Jesus and Mary were preserved from all sin throughout their whole lives by God supplying them with gifts and aids that He knew would always elicit a favorable free response from them. Presumably He could have done the same for others.

As Pruss puts $i^{4}$ :

It seems very likely that given Molinism and an infinite number of possible people to choose from, God could choose to create a large group that all choose rightly. There is no guarantee that God could do so, but it is extremely unlikely that the conditionals of free will would not allow it.

As Rasmussen (2004, pp. 459-60) puts it:

[W]hile it is possible that every essence suffers from TWD, the probability that every essence suffers from transworld depravity is zero, if the number of personal essences is infinite.

\section{As Zimmerman (2009, p. 75) puts it:}

[T]here was a chance, however small (though perhaps no smaller than the chances of transworld depravity), that God had found himself confronted by essences each of which displays transworld manipulability.

Plantinga (1974) himself, who first introduced Depravity in connection with the logical problem of evil, is careful to insist that Depravity is mere a logical possibility and never claims that it has anything above a low probability. Plantinga's (2004) own Molinist theodicy makes no use of Depravity. Thus, many people believe:

The Common Claim: We should assign a low probability to Depravity.

If these authors are right, and the Common Claim is true, this significantly reduces the relevance of Depravity to theodicy.

\section{The Argument from FINE-TUNING's LESSON}

The Lesson supports an argument against the Common Claim:

(1) The Lesson is true.

(2) If the Lesson is true, then the Common Claim is false.

(3) Therefore, the Common Claim is false.

(1) is motivated by Bertrand's Paradox and the Normalization and Coarse-Tuning Problems.

My initial defense of (2) relies on the idea that, given Molinism, we are in the dark about which distribution of truth-values to the counterfactuals of freedom God would 


\section{2 / AMERICAN PHILOSOPHICAL QUARTERLY}

end up working with prior to creation. This is just as, given our best physics, we are in the dark about which value the gravitational constant would take prior to creation. We have no reason to think God would end up working with one distribution rather than another. For this reason, it is tempting to use Indifference to assign probabilities to the relevant distributions. But if the Lesson is true, then Indifference is false due to Bertrand's Paradox. And, even setting that aside, there are infinitely many counterfactuals of freedom about infinitely many possible people and infinitely many ways to assign truth-values to them. So, applying Indifference would lead to variants of the Normalization and CoarseTuning Problems. So, we should not assign a low probability to Depravity and, therefore, the Common Claim is false.

My considered defense of (2) will rely on an examination of various ways in which one might try to get the result that the probability of Depravity is low without appealing to Indifference. I argue that further applications of the Lesson together with other assumptions the Molinist may embrace allow for replies to the objections.

\section{OBJECTIONS AND REPLIES}

First Objection: We are not in the dark about the probabilities of the distributions of truth-values to the counterfactuals of freedom. We can just look at how free creatures actually behave and extrapolate from that.

Reply: The proponent of this objection might have a point. But if so, their point supports the claim that the probability of Depravity is high. After all, when we look at how people actually behave, they all do evil. So, it must have been very likely that God would get stuck with free creatures that would all do evil. Compare: a fine-tuning skeptic might suggest that we aren't in the dark about how likely it is that the gravitational constant would fall within the life permitting range. After all, life exists doesn't it? So, it must have been very likely that the gravitational constant would end up somewhere in the life permitting range.

Second Objection: Free creatures seem to be good at not gouging out their eyes ${ }^{6}$. Suppose God creates a free creature and commands him not to gouge his eye. Suppose this is the only free being God ever creates and that this is the only free choice God ever gives him. Extrapolating from our own behavior, we can predict that he wouldn't gouge out his eye. So, it seems very likely that God could have created someone and put him in circumstances in which he would not have done anything evil ${ }^{7}$.

Reply: The proponent of Depravity should accept:

Biased Observations: Absent divinely-induced bias, intuitions about how merely possible free creatures would behave are unreliable.

It is not as though we randomly selected possible free creatures and watched them behave across a randomly selected range of possible circumstances. We observe free creatures and free decisions that were hand picked by God out of all the possible free creatures and free decisions He could have actualized. Furthermore, we do not have a large sample of observations of the behavior of free creatures in circumstances that are very unusual. Imagine, then, that almost all counterfactuals of freedom that say a free creature does something right are false. But, occasionally, God finds a true one that says a free creature in a highly populated world does what is right. And, very rarely, God finds a few true ones that say free creatures in the same highly populated world act rightly. And, exceedingly rarely, God finds a cluster of true counterfactuals of freedom about a large number of free creatures in the very same world saying that they often do right. But God is never able to find a collection of true counterfactuals of freedom that say together that all creatures in the same world always, or 
even almost always, do what is right. Given Biased Observations, for all we know a scenario like this is actual and so the creature in the example would gouge his eyes out.

Third Objection: Molinism must allow that a free creature's choices are responsive to desires and reasons. ${ }^{8}$ So, the probability that a free creature would choose a certain way is a function of that creature's desires and reasons in such a way that the stronger the desires and reasons for a choice are over the alternatives, the closer the probability the creature will make that choice is to one. So, God can make a free creature's choice for what is right be as likely as He wishes by making its desires and reasons in favor of the right over the wrong be as strong as possible.

Reply: The proponent of Depravity should accept:

Unequal Weight: Free creatures are responsive to desires and reasons in such a way that not all desires and reasons have the same weight in moving them to act.

One Depravity friendly scenario concerns:

R1: Being the originator of the world's evil.

R2: The triumph of good over evil.

R3: Flourishing in the face of suffering.

Suppose the probability a free creature will do evil for the sake of $\mathrm{R} 1$ is one minus infinitesimal no matter what other desires or reasons it has and the probability it will do good is zero plus infinitesimal unless that creature has R2 or R3 among its reasons. In that case, for any free creature that exists in any world that does not yet contain evil, that creature would have the opportunity to introduce evil on the basis of R1. And that creature would not yet have the opportunity to do anything good on the basis of R2 or R3. The probability that such a creature would do evil rather than good in that case is one minus infinitesimal.

Fourth Objection: Even if free creatures respond to $\mathrm{R} 1, \mathrm{R} 2$, and $\mathrm{R} 3$ in the way $\mathrm{I}$ have specified, that is not enough to secure Depravity. God could create creatures that do not know that they have the opportunity for introducing evil (e.g., they might not know that evil hasn't already been introduced). He could create creatures for which R1 just wouldn't occur as a reason because He'd prevent them from having R1 occur to them (and instead have some other reason occur to them).

Reply: R1 by itself is insufficient to secure Depravity. Nevertheless, Depravity may be secured with either R2 or R3. If free creatures behave in such a way that they will choose evil over good unless there is evil to overcome, then that is enough for Depravity to be true. If free creatures will choose evil over good unless they have the option of striving to flourish in reaction to suffering, then that is enough for Depravity to be true. To avoid this, God would have to deceive the first free creature by making it believe that either evil already exists or that it has suffering to overcome when it does not. But God is unable to engage in such deception. ${ }^{9}$ So, Depravity is true.

Fifth Objection: Rasmussen (2004) shows that Depravity is false. His argument relies not on Indifference but:

PPC: All counterfactuals of freedom should be assigned probabilities between zero and one.

So (2) is false.

Reply: Rasmussen holds that "PPC is based on the plausible supposition that if there are counterfactuals of creaturely freedom, then they are metaphysically contingent." So PPC is motivated by:

Regularity: All contingent propositions should be assigned probabilities between zero and one.

Regularity is rejected by Easwaran (2014), Pruss (2013) and (2014), and Williamson (2007). As Fitelson and Hájek (forthcoming, p. 4) put it, "Probability theory and statistics are shot through with non-trivial zeroprobability events.... [G]enuine possibilities 


\section{4 / AMERICAN PHILOSOPHICAL QUARTERLY}

that receive probability 0 , and interesting ones at that."

Sixth Objection: Rasmussen-style arguments can be constructed with:

Independence: Counterfactuals of freedom about creatures in radically different circumstances are statistically independent.

There are infinitely many radically different circumstances in which God could put a first free creature. Given Independence, there must be infinitely many statistically independent counterfactuals of freedom about them. It is very likely that some of them will come out in such a way that Depravity is false.

Reply: The proponent of Depravity should assume that what makes differences in circumstances generate statistical independence is that they provide free creatures with distinct reasons and desires. The circumstances of any first creature will be similar to the circumstances of any other such creature in one respect: They will have $\mathrm{R} 1$ as a reason to do evil but not R2 or R3 as a reason to do good. So, if free creatures are responsive to $\mathrm{R} 1$, $\mathrm{R} 2$, and R3 in the way discussed above, then the circumstances of all first free creatures in all possible circumstances will be similar in such a way that they are not statistically independent. The probability that all first free creatures will do evil is one minus infinitesimal. This result is compatible with an even stronger assumption:

Complete Independence: All counterfactuals of freedom are statistically independent.

If free creatures with R1 but not R2 or R3 have probability of one minus infinitesimal of doing evil, then the probability of Depravity is not low even if all counterfactuals of freedom are statistically independent. On the other hand, if one rejects Complete Independence and maintains that counterfactuals of freedom about creatures with the same reasons and desires are not statistically independent, then one can respond to these objections with a much weaker assumption: Suppose the probability a free creature with R1 but not R2 or $\mathrm{R} 3$ will do evil is .3. Then, given that free creatures with the same reasons and desires will act in the same ways, the probability that all first free creatures will do evil in the first free choice is .3. So, the probability of Depravity is not particularly low.

Seventh Objection: I have been exploring two distributions of truth-values to the counterfactuals of freedom that are friendly to Depravity.

D1: Absent divinely-induced bias, free creatures will nearly always choose evil over good.

D2: Free creatures respond to reasons and desires in such a way that as a world's evil is decreased, the probability that such creatures will choose evil is increased.

Endorsing either of these requires denying intuitive and commonsense claims about how freewill works.

Reply: The proponent of Depravity should accept:

Outweighed: The cost of denying intuitive, commonsense claims is outweighed by

(i) a significant gain in explanatory power,

(ii) an independently motivated error theory, and

(iii) the ability to provide systematic and useful paraphrases of the relevant claims.

Lewis (1986) uses (i) to defend modal realism. He grants that the view is extremely counterintuitive and that the incredulous stare is a cost of the theory..$^{10}$ But he suggests that, nevertheless, the explanatory power of modal realism outweighs its counterintuitiveness. Smolin (2001) and contributors to Leslie (1998) use (i) to defend the multiverse hypothesis. It may be, as Wallace (2012, p. 421) puts it, "surprising-perhaps even shockingand highly counterintuitive" to posit a multiverse. But the explanatory power of doing so, such authors suggest, outweighs the counterintuitiveness of the multiverse hypothesis. In 
the case at hand, the truth of Depravity would explain why God allows evil. For if Depravity is true, then God was unable to create a world in which free creatures always refrained from evil. That is a significant gain in explanatory power.

(ii) has been used to defend mereological universalism and nihilism (Rose and Schaffer, 2017), rejection of the passage of time and rejection of endurantism (Paul, 2010), eliminativism about consciousness (Dennett, 1991), and the Buddhist doctrine of No-Self (Chadha, forthcoming). In the case at hand, Molinism and the Lesson together suggest an error theory for anti-Depravity intuitions that is independent of Depravity: God doesn't just randomly select for free decisions out of all the possible ones. His selection is biased in favor of His plans. Our intuitions about how free creatures will behave in randomly selected merely possible circumstances are therefore based on extrapolation from a biased sample. And that is an unreliable belief forming process. There is still the intuition that Depravity is false because the range of Depravity friendly assignments of probabilities to the truth-values of counterfactuals of freedom is so small. But such intuitions are generated by Indifference and are therefore unreliably formed.

(iii) has been used to defend merelogical nihilism (van Inwagen (1990)), monism (Schaffer (2007) and Sider (2007)), counterpart theory (Lewis (1986)), utilitarianism (Hare (1981)), skepticism (Unger (1981)), and ontological indeterminism (Chalmers (2009)). Regarding D1, imagine I am wondering whether to pass my friend a screwdriver. Intuitively, it seems that the counterfactual "If I were to pass my friend the screwdriver, he would not stab me to death" is true. But if we assume divinely-induced bias is absent, then given D1, this counterfactual of freedom is almost certainly false. However, there is a paraphrase available. In particular,
"Given divinely-induced bias, if I were to pass my friend the screwdriver, he would not stab me to death." And since there is in fact divinely-induced bias, this paraphrase is useful. Regarding D2, there is no need to provide a paraphrase. For we live in a world with plenty of evil. So, in ordinary contexts, counterfactuals of freedom have the truthvalues they seem to have.

Eighth Objection: But this is just skepticism! The idea that creatures respond to R1, $\mathrm{R} 2$, and R3 in this way has absolutely nothing going for it. I am merely offering a skeptical hypothesis. It may be dismissed.

Reply: It is important to distinguish between a mere skeptical hypothesis and a skeptical result that is supported with argument. If had simply highlighted a skeptical possibility regarding anti-Depravity intuitions and left it at that, I would agree that what I have said should be dismissed. But I have argued for the relevant skeptical result. That argument is what the idea that creatures respond to R1, R2, and R3 in a Depravity friendly way has going for it. My argument is this: Given Molinism, anti-Depravity intuitions are generated by Indifference and observational bias. These are unreliable belief forming processes. Rejecting such intuitions yields a gain in explanatory power. And I have offered a useful paraphrase in place of the relevant intuitions. If intuitions are formed by unreliable processes, if rejecting those intuitions yields a gain in explanatory power, and if the intuitions can be replaced with a useful paraphrase, then such intuitions should be rejected. Thus, given Molinism, anti-Depravity intuitions should be rejected. Perhaps mere skeptical possibilities should be dismissed. But engagement with arguments supporting skeptical results is widespread in philosophy and that is as it should be. I discussed some skeptical arguments about intuitions regarding the passage of time, the composition of objects, the self, and consciousness in reply 


\section{6 / AMERICAN PHILOSOPHICAL QUARTERLY}

to the previous objection. Skeptical arguments about intuitions regarding non-causal realism have been defended by Benacerraf (1973), Field (1989), Street (2006), Warren (2017). I have defended such skepticism as well in [Anonymized]. Skeptical arguments about freewill have been defended by
Pereboom (2001) and in the contributions to Caruso (2013). I see no basis for taking other skeptical arguments seriously but dismissing without engagement a skeptical argument regarding Molinism and freewill.

AFFILIATION?

\section{NOTES}

For comments and discussion I thank Mike Bertrand, Jody Graham, Bob Gruber, Ryan Hebert, Luis Oliveira, Kristian Olsen, Kenny Pearce, and Joshua Rasmussen. Special thanks to Felipe Leon, Alexander Pruss, and numerous anonymous reviewers.

1. See van Fraassen (1989) and Hájek (2012).

2. I accept the Lesson. But I follow Hawthorne and Isaacs (manuscript, p. 12) in thinking that the Lesson is irrelevant to the fine-tuning argument. In particular, when physicists arrive at the judgment that the probability the universe would allow for life is low, they do not base their judgment on Indifference. The appeal to Indifference is something philosophers mistakenly attribute to them. In general, in the main text I am trying to make as many standard assumptions as possible. Where I differ from a standard position, I will state that difference in a footnote.

3. Libertarianism is part of the standard formulation of Molinism. But I follow Perszyk (1998), (2000), and (2003) in thinking Molinism fits better with compatibilism.

4. See Plantinga (1974).

5. http://alexanderpruss.blogspot.com/2016/04/two-kinds-of-free-will-theodicies.html

6. This objection was originally discussed by Alexander Pruss. See: http://alexanderpruss.blogspot. com/2016/06/an-argument-that-trans-world-depravity.html

7. See Otte (2009) and Pruss (2012).

8. This objection was originally discussed by Felipe Leon. See: http://exapologist.blogspot. com/2012/03/is-plantingas-free-will-defense.html

9. This is the traditional view. My own view, discussed in Hill 2014, is that God is able to deceive. So, my own view is the Molinist is better off accepting something that is not quite Depravity. It is instead that, given Molinism, for all we know any world with free creatures will contain evil or God will systematically deceive every inhabitant in that world about whether there is evil to overcome and whether it has suffered.

10. One cost of Molinism that must be taken into account is the grounding objection discussed by Adams (1997) and Andrews, Thurow, and Hochsetter (2014). However, it can be mitigated somewhat. Although it is obscure what grounds counterfactuals of freedom, it is not obscure how they could have an explanation (See Pruss and Rasmussen (2014)). In addition to the Pruss/Rasmussen strategy, it seems to me that counterfactuals of freedom can be explained in terms of the beliefs, desires, and reasons of the agents of those counterfactuals of freedom. Furthermore, the grounding objection does not apply to Perszyk's (2000) compatibilist version of Molinism. 


\section{REFERENCES}

Adams, Robert. 1977. "Middle Knowledge and the Problem of Evil," American Philosophical Quarterly, vol. 14, no. 2, pp. 109-117.

Andres, Paul, Joshua Thurow, and Kenneth Hochstetter. (2014). "On Counterfactuals of Libertarian Freedom: Is There Anything I Would Have Done if I Could Have Done Otherwise?" American Philosophical Quarterly, vol. 51, no. 1, pp. 85-94.

Benacerraf, Paul. 1973. "Mathematical Truth," Journal of Philosophy, vol. 70, no. 19, pp. 661-680.

Caruso, G. 2013. Exploring the Illusion of Free Will and Moral Responsibility (Lexington: Lexington Books).

Chadha, Monima. 2018. "No-Self and the Phenomenology of Ownership," Australasian Journal of Philosophy, vol. 96, no. 1, pp. 14-27.

Colyvan, Mark, Garfield, Jay, Priest, Graham. "Problems with the Argument from Fine Tuning," Synthese, vol. 145, no. 3, pp. 325-338.

Chalmers, David. 2009. "Ontological Anti-Realism," in Metametaphysics: New Essays on the Foundations of Ontology, ed. Chalmers, Manley, and Wasserman (Oxford: Oxford University Press).

Craig, William. 1994. "Robert Adams's New Anti-Molinist Argument," Philosophy and Phenomenological Research, vol. 54, no. 4, pp. 857-61.

Dennett, Daniel. 1991. Consciousness Explained (The Penguin Press).

Easwaran, Kenneth. 2014. "Regularity and Hyperreal Credences." The Philosophical Review, vol. 123, no. 1 , pp. $1-41$.

Flint, Thomas. 2011. "Whence and Wither the Molinist Debate: A Reply to Hasker," in Molinism: The Contemporary Debate, ed. Perszyk.

Field, Hartry. (1989). Realism, Mathematics and Modality (Oxford: Blackwell).

Fitelson, Brandon and Alan Hájek. 2017. "Declarations of Independence," Synthese, 3979-3995.

Hájek, Alan. 2012. "Interpretations of Probability," in The Stanford Encyclopedia of Philosophy, ed. Zalta, URL $=<$ http://plato.stanford.edu/archives/win2012/entries/probability-interpret/>.

Hare, Richard. 1981. Moral Thinking: Its Levels, Methods, and Point (Oxford University Press).

Hawthorne, Jonathan, and Yoaav Isaacs. (Forthcoming). "Misapprehensions About the Fine-Tuning Argument," pp. 1-16.

Hill, Scott. 2014. "Giving up Omnipotence," Canadian Journal of Philosophy, vol. 44, no. 1, pp. 97-117. - 2016. "From Isolation to Skepticism," Erkenntnis, vol. 81, no. 3, pp. 649-668.

Howard-Snyder, Daniel. 2013. "The Logical Problem of Evil: Mackie and Plantinga," in The Blackwell Companion to the Problem of Evil ed. McBrayer and Howard-Snyder.

Leslie, John. 1998. Physical Cosmology and Philosophy (Macmillin).

- 1986. On the Plurality of Worlds (Oxford University Press).

1993. "Evil for Freedom's Sake?" Philosophical Papers, vol. 22, no. 3, pp. 149-172.

McGrew, Timothy, Lydia McGrew, and Eric Vestrup. 2001. "Probabilities and the Fine-Tuning Argument: A Skeptical View," Mind, vol. 110, no. 440, pp. 1027-1038.

Otte, Richard. 2009. "Transworld Depravity and Unobtainable Worlds," Philosophy and Phenomenological Research, vol. 78, no. 1, pp. 165-177.

Perszyk, Kenneth. 1998. "An Anti-Molinist Argument," Philosophical Studies, vol. 90, no. 3, pp. 215-235.

Perszyk, Kenneth. 2000. "Molinism and Compatibilism," International Journal of Philosophy of Religion, vol. 48, no. 1, pp. 11-33.

Perszyk, Kenneth. 2003. "Molinism and the Consequence Argument," Faith and Philosophy, vol. 20, no. 2, pp. 131-151.

Paul, Laurie. 2010. “Temporal Experience,” The Journal of Philosophy, vol. 107, no. 7, pp. 333-59.

Pereboom, Derk. 2001. Living Without Freewill (Cambridge University Press). 


\section{8 / AMERICAN PHILOSOPHICAL QUARTERLY}

Plantinga, Alvin. 1974. The Nature of Necessity (Oxford University Press).

- 2004. "Supralapsarianism, or 'O Felix Culpa,", in Christian Faith and the Problem of Evil, ed. Peter van Inwagen (Eerdmanns).

Pruss, Alexander. 2012. "A Counterexample to Plantinga's Free Will Defense," Faith and Philosophy, vol. 29, no. 4, pp. 400-15.

. 2013. "Probability, Regularity, and Cardinality," Philosophy of Science, vol. 80, no. 2, pp. $231-240$.

- 2014. "Regular Probability Comparisons Imply the Branch-Tarski Paradox," Synthese, vol. 191, no. 15 , pp. 3525-3540.

, and Joshua Rasmussen. 2014. "Explaining Counterfactuals of Freedom," Religious Studies, vol. 50, no. 2, pp. 193-8.

Rasmussen, Joshua. 2004. "On Creating Worlds Without Evil-Given Divine Counterfactual Knowledge," Religious Studies, vol. 40, no. 4, pp. 457-470.

Rose, David, and Jonathan Schaffer. 2017. "Folk Mereology is Teleological," Nous, vol. 51, no. 2, pp. 238-270.

Schaffer, Jonathan. 2007. "From Nihilism to Monism," Australasian Journal of Philosophy, vol. 85, no. 2 , pp. 175-91.

Sider, Theodore. 2007. "Against Monism," Analysis, vol. 67, no. 1, pp. 1-7.

Smolin, Lee. 2001. The Life of the Cosmos (Oxford University Press).

Street, Sharon. 2006. "A Darwinian Dilemma for Realist Theories of Value," Philosophical Studies, vol. 127, no. 1, pp. 109-66.

Unger, Peter. 1975. Ignorance: A Case for Skepticism (Oxford University Press).

Van Fraassen, Bas. 1989. Laws and Symmetry (Oxford University Press).

Van Inwagen, Peter. 1990. Material Beings (Cornell University Press).

Wallace, David. 2012. The Emergent Multiverse: Quantum Theory According to the Everett Interpretation (Oxford University Press).

Warren, Jared. 2017. “Epistemology versus Non-Causal Realism,” Synthese, vol. 194, no. 5, pp. 1643-62.

Wierenga, Edward. 1989. The Nature of God: An Inquiry into Divine Attributes (Cornell University Press).

Williamson, Timothy. 2007. "How Probable is an Infinite Sequence of Heads?" Analysis, vol. 67, no. 3, pp. 173-180.

Zimmerman, Dean. 2009. "Yet Another Anti-Molinist Argument" in Metaphysics and the Good, ed. Jorgensen and Newlands (Oxford University Press), pp. 33-94. 